\title{
O feedback nas práticas profissionais de peritos contábeis no Ministério Público
}

\author{
Feedback and Professional \\ Practices of Accounting Experts \\ in the Public Prosecutor's Office
}

\author{
ARIEL PRATES \\ Universidade Federal do Rio Grande do Sul. \\ JONATAS DUTRA SALLABERRY \\ Universidade Federal de Santa Catarina. \\ LEONARDO FLACH \\ Universidade Federal de Santa Catarina. \\ IVAM RICARDO PELEIAS \\ Fundação Escola de Comércio Álvares Penteado. \\ ROMINA BATISTA DE LUCENA DE SOUZA \\ Universidade Federal do Rio Grande do Sul.
}

\section{RESUMO}

O feedback está relacionado com aprendizagem que traz benefícios para os indivíduos e às organizações. No cenário brasileiro em que o combate à corrupção e à prática de crimes financeiros passa a ser percebido como relevante pela sociedade, surge a necessidade de conhecer o ambiente de trabalho dos agentes responsáveis pela investigação financeira. Esta pesquisa tem como objetivo analisar como ocorre o feedback para o desenvolvimento da aprendizagem e sua importância para as práticas profissionais dos Peritos Contábeis do Ministério Público. A literatura aponta que um bom trabalho pericial está relacionado à objetividade, rigor tecnológico, concisão, argumentação, exatidão, e clareza. Essa avaliação precisa ser realizada por terceiros, independentes, o que, pelas características das peças periciais torna essa avaliação realizada quase que exclusivamente pelos usuários do produto. Esta é uma pesquisa descritiva e qualitativa, empregando o método de entrevista dirigida com os profissionais. A pesquisa 
revelou a carência do feedback acerca do trabalho realizado, bem como indica a percepção de importância deste retorno para os peritos entrevistados, que indicaram as conseqüências causadas pela ausência de um processo de feedback, bem como a indicação de sugestões e reflexões sobre este processo.

Palavras-chave: perícia contábil; feedback; laudos; forense.

\section{Abstract}

Feedback is about learning that brings benefits to individuals and organizations. In the Brazilian scenario where the fight against corruption and the practice of financial crimes is perceived as relevant by society, there is a need to know the work environment of the agents responsible for financial investigation. This research aims to analyze how feedback occurs for the development of learning and its importance to the professional practices of the Accounting Experts of the Public Prosecution Service. The literature points out that good expert work is related to objectivity, technological rigor, conciseness, argumentation, accuracy, and clarity. This evaluation must be carried out by independent third parties, which, due to the characteristics of the expert parts, makes this assessment carried out almost exclusively by the users of the product. This is a descriptive and qualitative research, using the method of directed interview with the professionals. The research revealed the lack of feedback about the work performed, as well as indicates the perception of importance of this feedback to the experts interviewed, who indicated the consequences caused by the absence of a feedback process, as well as the indication of suggestions and reflections on this process. Keywords: accounting expertise; feedback; reports; forensic.

\section{INTRODUÇÃO}

O Brasil é o país com o maior número de processos per capita, o que demonstra a complexidade e o tamanho do desafio que é montar e manter um sistema judiciário eficiente, justo e rápido para atender à demanda (OLONGO, 2014). Nesse cenário, cada vez mais se fazem presentes - e necessários - os esforços do perito contábil como auxiliar da justiça. Nessa linha, os analistas da área de perícia e especialidade em contabilidade do Ministério Público 
Federal possuem como objetivo o auxílio à justiça, respondendo diretamente aos Procuradores da República.

Como importantes colaboradores do Poder Judiciário, os peritos contábeis auxiliam os juizes na solução dos litígios (BLEIL; SANTIM, 2008; NEVES JUNIOR; MOREIRA, 2011). Essa necessidade de auxiliar a justiça se deve, entre outros fatores, ao fato do Brasil ser, na percepção da população, o $76^{\circ}$ país menos corrupto (TRANSPARENCY, 2015). Aliado a isso, desde os escândalos envolvendo a Petróleo Brasileiro S.A. (PETROBRÁS), desde 2014 o país vem caindo posições nesse ranking (MARTINS, 2016).

A perícia contábil é, conforme Bastos (2013), de grande relevância para a atuação do Ministério Público Federal (MPF), tanto na esfera criminal (para a propositura da ação penal), servindo como instrumento de prova; quanto na esfera cível, especialmente em casos de improbidade administrativa, no âmbito extrajudicial.

O profissional deve registrar, de forma abrangente, o conteúdo da perícia contábil, particularizando aspectos e minudências que envolvam o seu objeto (CFC, 2015). Seja um laudo, seja um parecer, o perito busca, com o resultado de seu trabalho auxiliar o juiz na solução de questões contábeis na lide apreciada no âmbito judicial, visto que tais peças auxiliam o trabalho dos juízes, especialmente no ato decisório (BLEIL; SANTIM, 2008; MENDONÇA et al., 2012; FERREIRA et al., 2012; NEVES JUNIOR et al., 2013), enquanto no âmbito extrajudicial tem como foco esclarecer fatos para a parte contratante.

A qualidade do parecer técnico elaborado pelos analistas do MPF é de papel relevante para o propósito do órgão, pois esta peça técnica visa esclarecer fatos contábeis aos Procuradores, os quais nem sempre possuem domínio sobre a matéria contábil do processo em questão. Na esfera trabalhista, Ferreira et al. (2012) e Neves Júnior et al. (2013) apontam que, para os juízes da Justiça do Trabalho, os laudos e pareceres são instrumentos chave na prolação da sentença, mas que considerável quantidade dessas peças são de baixa qualidade; na esfera cível, Anjos et al. (2010) encontraram resultados semelhantes após analisarem os laudos nas Varas Cíveis Estaduais de Maceió. Até o momento, não foram localizados estudos que verifiquem a qualidade do laudo no âmbito federal, tampouco 
se tais peças atendem seu propósito, ou se um sistema de feedback seria necessário para a prática profissional desses analistas.

Entre os elementos prévios da pesquisa foi identificado que, no âmbito profissional, os Analistas periciais do MPF não têm conhecimento do andamento processual após a juntada de seu parecer aos autos. Isso significa que informações sobre a qualidade do produto entregue por eles, bem como a aceitação da peça por parte do Procurador da República ou do juiz da Justiça Federal não são, via de regra, de conhecimento dos analistas.

Isso posto, esse estudo visa responder, na percepção de analistas da área de perícia e especialidade em contabilidade lotados no $\mathrm{MPF}$, como ocorre o processo de feedback e qual a sua importância para as práticas profissionais de analistas da área de perícia e especialidade em contabilidade lotados no MPF? Esta pesquisa tem como objetivo analisar como ocorre o feedback para o desenvolvimento da aprendizagem e sua sua importância para as práticas profissionais dos Peritos Contábeis do Ministério Público Federal (MPF) e desenvolvimento institucional. Foram realizadas 12 entrevistas presenciais no período entre junho e julho de 2017. Foram entrevistados analistas periciais em uma unidade de serviços recém criada, para apoio aos trabalhos dos procuradores de justiça. A justiça reconhece a importância e a utilidade da perícia contábil, do contrário, não criariam essa unidade

O trabalho visa ocupar a lacuna teórica da inexistência de pesquisas acadêmicas que analisem as práticas profissionais dos peritos do Ministério Público Federal, uma carreira recente de apoio técnico direto ao agente da acusação criminal, bem como estudos que abordem o feedback nas práticas periciais contábeis. Destaca-se a relevância da pesquisa pelo fato desse órgão ser uma das partes indepententes e autônomas no processo judicial, além do seu papel exclusivo na análise da oportunidade de denúncia criminal. Conhecer o processo de ocorrência e suas peculiaridades pode contribuir para a construção de uma cultura ou sistema de feedback que contribua para uma maior efetividade do produto pericial, seja no próprio órgão ou em outras unidades semelhantes.

O feedback é considerado por autores um aspecto importante a ser analisado no processo de produção pericial. Na medida em que se estabeleça um entendimento sobre o sistema e canais para feedback, 
os analistas periciais poderão melhorar suas práticas profissionais, dimensionar melhor suas atividades e recursos de que necessitam, além de cuidarem de sua educação continuada e reciclagem técnica profissional.

No âmbito da Polícia Federal, Martinez (2013) analisou a efetividade dos laudos periciais de informática e destacou a necessidade do feedback, entre outros fatores, para a melhoria do processo e maior efetividade da persecução penal. Tsunoda (2011) exaltou a abertura e a necessidade do estudo mais aprofundado acerca do feedback dos operadores do direito em relação ao Laudo Pericial. Sob o aspecto motivacional, justifica-se a necessidade de pesquisas sob o feedback em diversos estudos (CAVEDON, 2009; CARVALHO, 2012; TSUNODA, 2012; GUALDA, 2013).

\section{FUNDAMENTAÇÃo TEÓRICA}

Os analistas do MPF respondem diretamente aos Procuradores da República. No âmbito judicial, o MPF atua sob três enfoques. O primeiro, como fiscal da lei, especialmente como interveniente nos processos cíveis, em mandados de segurança, ações ordinárias e precatórios (BRASIL, 2010). Isso ocorre quando o MPF não faz parte da relação do processo, como autor ou como réu. A tarefa do Ministério Público Federal é apenas verificar, fundamentado na legislação, se aquela demanda do juiz merece ou não ser atendida (BRASIL, 2010).

O segundo escopo de atuação do MPF, na área cível, corresponde à defesa dos interesses: difusos (de toda a sociedade, não específicos a um indivíduo apenas); coletivos (interesses de um grupo, categoria ou classe); e individuais homogêneos (têm um fato gerador comum, e atinge as pessoas individualmente e da mesma forma), agindo por meio da ação civil pública ou coletiva ou da ação de improbidade administrativa (BRASIL, 2017). O terceiro segmento de atuação do MPF é a área criminal, cabendo a ele promover a ação penal pública.

A atuação é considerada extrajudicial quando os membros do MPF agem independentemente da vinculação a um juízo (BRASIL, 2010). Fora da esfera judicial e antes da proposição de ação à Justiça, o MPF pode realizar medidas administrativas, tal qual inquéritos 
civis públicos, recomendações, termos de ajustamento de conduta e audiências públicas (BRASIL, 2017). Caso sejam comprovadas [com o auxílio ou não do parecer técnico contábil] irregularidades, o MPF pode ingressar com ação judicial (BRASIL, 2017).

\subsection{Perícia Contábil}

Do latim peritia, costuma-se empregar o termo perícia como sinônimo de saber, talento (SÁ, 2011) e conhecimento (HOOG, 2017). É um "instrumento especial de constatação, prova ou demonstração, científica ou técnica, da veracidade de situações, coisas ou fatos" (ALBERTO, 2012). Para Fagundes et al. (2008), a perícia tem como objetivo principal esclarecer a verdade e, para isso, tem que ser confiável, imparcial e merecedora de fé, sem subjetividade. Os fatos são então transferidos para o ordenamento da instância decisória (ALBERTO, 2012), a fim de orientar uma autoridade formal no julgamento de um fato, ou desfazer conflito em interesses de pessoas (MAGALHÃES et al., 2009).

Para Fagundes et al. (2008) e Sá (2011) um bom trabalho pericial está relacionado à: i) Objetividade: caracteriza-se pela ação do perito em não se desviar do assunto em questão; ii) Rigor tecnológico: deve limitar-se ao que é reconhecido como científico no campo da subjetividade; iii) Concisão: precisa ater-se ao assunto, respondendo satisfatoriamente à questão e evitando o prolixo; iv) Argumentação: caracterizado por demonstrar em que se baseia para apresentar sua opinião; v) Exatidão: definido pela absoluta certeza sobre os fatos a que está opinando, baseado única e exclusivamente em fatos concretos; e vi) Clareza: uso de uma linguagem acessível, observando quem será o leitor do seu trabalho.

Neves Júnior et al. (2013) destacam a qualidade e a relevância dos serviços do perito, visto que o laudo e o parecer servirão de base para a tomada de decisão pelo juiz. Magalhães et al. (2009) complementam que a apresentação dessas peças é fator de grande importância, haja vista que, mesmo o perito nomeado e/ou o assistente técnico realizando um excelente trabalho técnico e científico, se seus trabalhos não estiverem adequadamente apresentados, isentos de erros e rasuras, a receptividade pelo juiz e pelas partes pode ser afetada. 
A perícia contábil, no âmbito das investigações, opera como prova judicial, podendo fornecer os subsídios necessários ao desembaraço das questões controversas (NEVES JUNIOR; MOREIRA, 2011). Ela deve ser bem compreendida pelas partes, pois a falta de uma boa estrutura pode afetar, por exemplo, a União e os cofres públicos (NEVES JUNIOR; COSTA; PEREIRA, 2008).

Nesse contexto, há carências na elaboração do laudo e do parecer, tais como: falta de descrição de parâmetros e sua fundamentação para a elaboração dos laudos; uso de textos rebuscados; utilização em excesso de termos técnicos; uso de palavras de sentido dúbio ou impreciso (MEDEIROS; NEVES JUNIOR, 2006); falta de conhecimento jurídico (MENDONÇA, et al., 2012); e omissões importantes, como a categoria profissional do perito (CESTARE; PELEIAS; ORNELAS, 2010). Assim sendo, a formação dos peritos carece de mais atenção, de forma que possa contribuir para a boa qualidade de seu trabalho, tornando-o esclarecedor e de grande ajuda sobre a controvérsia periciada (NEVES JUNIOR et al., 2013). Uma forma de melhorar o trabalho pericial é o feedback aos seus autores, que trataremos a seguir.

\subsection{Feedback}

Para que possa melhorar o próprio desempenho, o profissional precisa, concomitantemente, conhecer o que dele se espera (prioridades, resultados esperados e repectiva avaliação), retroação, também denominada feedback, sobre o que faz, em que o conhecimento dos resultados obtidos pela sua atuação é de grande importância para a correção e o aprimoramento do desempenho da pessoa em seu trabalho sendo parte do monitoramento que avalia se uma nova decisaão precisa ser tomada (DAFT, 2007; CHIAVENATO, 2016).

Feedback pode ser entendido como a capacidade de dar e receber opiniões, críticas e sugestões sobre algo pessoal ou profissional (MOREIRA, 2009). Assim, consiste na percepção do emissor sobre a reação do receptor à mensagem ou produto confeccionado por aquele. No caso da perícia contábil, o emissor é o Perito e a mensagem emitida é o Laudo ou Parecer Pericial; enquanto a reação esperada seria da autoridade judiciária a quem cabe o convencimento ou não dos elementos apresentados pelos Peritos. 
Conceitos da área de educação podem ser úteis ao entendimento do feedback sobre o produto pericial. Chaudron (1977) definiu o feedback corretivo como qualquer reação do professor (autoridade) que claramente transforma, desaprova, ou exige reformulação do enunciado do aluno, caso este não apresente uma resposta adequada. No caso do trabalho pericial, não se propõe a discussão do objeto do conteúdo apresentado, mas da utilidade e compreensibilidade desse conteúdo, para quem precisa tomar uma decisão com base no produto do trabalho do Perito Contábil.

Esse profissional, como prestador de serviço técnico, mantendo a isenção e a interpretação técnica adequada, sujeita-se a entregar um produto útil ao cliente, que no caso precisa desse produto técnico contábil para tomar uma decisão fundamentada. O feedback tem poder transformador, por influenciar os autores sobre qualidades a potencializar e limitações a corrigir, indicar procedimentos e modelos gráficos, com vistas a apresentar um conteúdo técnico contábil a ser interpretado sem viés por um operador do direito.

Em seu estudo, Davis, Farrell e Ogilby (2010) questionaram 126 Procuradores que utilizam os serviços de contadores forenses e 603 contadores da área pública, com o intuito de identificar quais as causas de trabalhos mal feitos pelos contadores forenses norte-americanos. Os resultados encontrados estão expressos na Tabela 1.

Tabela 1 Causas de trabalhos mal feitos por contadores forenses

\begin{tabular}{lll}
\hline & Procs & CP \\
\hline Incapacidade de simplificar as informações & $89 \%$ & $66 \%$ \\
Comunicação oral ineficaz & $80 \%$ & $68 \%$ \\
Incapacidade de entender os objetivos de um caso & $67 \%$ & $55 \%$ \\
Incapacidade de identificar questões-chave & $65 \%$ & $72 \%$ \\
Falta de intuição investigativa & $57 \%$ & $68 \%$ \\
Comunicação escrita ineficaz & $40 \%$ & $64 \%$ \\
Incapacidade de sintetizar & $56 \%$ & $49 \%$ \\
Inflexível / de mente fechada & $47 \%$ & $59 \%$ \\
Outros & $3 \%$ & $4 \%$ \\
\hline
\end{tabular}

Fonte: Davis, Farrell e Ogilby (2010, traduzido pelos autores).

Conforme apurado por Davis, Farrell e Ogilby (2010), a comunicação, seja escrita, seja falada; o correto entendimento da tarefa a ser realizada; e a falta de habilidades investigativas são os principais entraves para o contador forense nos Estados Unidos. 


\section{Procedimentos metodológicos}

Essa pesquisa possui natureza aplicada. Gil (2008, p. 27) explica que estudos assim enquadrados tem o "interesse na aplicação, utilização e consequências práticas dos conhecimentos. Sua preocupação está menos voltada para o desenvolvimento de teorias de valor universal que para a aplicação imediata numa realidade circunstancial". Neste tipo de pesquisa, há a necessidade de contribuir para fins práticos, buscando soluções para problemas concretos (CERVO; BERVIAN; SILVA, 2007),

Quanto à abordagem do problema, a pesquisa possui características qualitativas, pois busca-se tratar significados, motivos, aspirações e crenças concernentes a um nível mais profundo das relações, a que não podem ser reduzidos à operacionalização de variáveis (MINAYO, 2007). Essa abordagem visa a relatar o mundo externo e entender os fenômenos sociais internos, buscando esmiuçar a maneira pela qual as pessoas constroem o mundo à sua volta, $\mathrm{O}$ que estão fazendo ou o que está acontecendo (FLICK, 2011; VIEIRA; RIVERA, 2012).

Quanto aos objetivos, a pesquisa classifica-se como descritiva. Estudos descritivos visam descrever as características de determinada população, incluindo o levantamento de opiniões, atitudes e crenças (GIL, 2017). Esse tipo de pesquisa analisa e correlaciona fatos e fenômenos sem manipulá-los, buscando descobrir a frequência em que um fenômeno ocorre (CERVO; BERVIAN; SILVA, 2007).

Quanto aos procedimentos, classifica-se como levantamento por meio de entrevista, com traços etnográficos, que estudam a cultura e o comportamento de determinados grupos sociais (ANGROSSINO, 2009). O propósito é o estudo das pessoas em seu ambiente de trabalho, a fim de estudar as múltiplas manifestações de um grupo de pessoas (GIL, 2017).

Para a coleta de dados, optou-se pela realização de entrevistas presenciais, em que se questionou a ocorrência (ou não) do feedback sobre o trabalho prestado pelos analistas da área pericial contábil lotados no MPF. A técnica de entrevista é bastante utilizada nas ciências sociais, sendo eficiente para obtenção de dados em profundidade acerca do comportamento humano (GIL, 2008). Há grande interação e conhecimento das realidades dos informantes, valorizando sua criatividade e espontaneidade, conjuntamente com 
a presença do entrevistador (COLAUTO; BEUREN, 2006).

A população desse estudo, coletado em maio de 2017, compreende os 44 analistas da área de perícia e especialidade em contabilidade lotados no MPF. Por acessibilidade, optou-se pela realização de entrevistas apenas no Distrito Federal e nos estados do Rio Grande do Sul, Paraná e São Paulo, o que implica em uma amostra não-probabilística intencional. Assim, a amostra final dessa pesquisa compreendeu 12 analistas, dos quais nove são vinculados à SEAP (Secretaria de Apoio Pericial) e três à SPEA (Secretaria de Pesquisa e Análise).

Para a respectiva análise dos dados, optou-se pela análise de conteúdo, que tem por objetivo "estudar as comunicações entre os homens, com maior ênfase no conteúdo das mensagens" (COLAUTO; BEUREN, 2006, p. 137). Nesse sentido, Richardson (1999, p. 224) infere que esse tipo de análise "busca compreender melhor um discurso, aprofundar suas características gramaticais [...] e extrair os momentos mais importantes". Para extração e evidenciação dos recortes, foi empregado o apoio do software NVIVO 11.

A categoria analisada foi a de 'feedback', definida como o retorno, resposta ou recompensa decorrente da entrega de um produto pericial aos seus usuários, em nível mais próximo ou mais distante. Embora indagados diretamente sobre o construto, os respondentes podem responder por termos semelhantes ou elípticos, o que demanda um maior aprofundamento do pesquisador no conteúdo analisado, para entender seu uso e interpretar as respostas. As respostas foram categorizadas e segmentadas em Problemas, Consequências, Sugestões e Outras observações, evidenciados no resultado.

A preocupação de Castro e Rezende (2018), sobre as pesquisas qualitativas, de validade interna, externa e a confiabilidade é evidenciada na pesquisa em distintos pontos. A validade interna revela-se na análise do conteúdo apresentado no capítulo de análise dos dados, por meio da premissa do estabelecimento de relações causais entre os construtos ou variáveis (YIN, 2013), para defesa das conclusões da pesquisa (GIBBERT; RUIGROK,2010).

A validade externa, sobre como os resultados podem ser generalizáveis, fica limitado pela escassez de publicações sobre o microtema. No entanto há de se considerar a potencialidade do contexto 
para que seja estudado de forma extendida para além do caso imediato (YIN, 2013; CASTRO; REZENDE, 2018). A confiabilidade é assegurada pela repetição dos resultados sob mesmas condições e mesmos procedimentos em diferentes ocasiões (YIN, 2013; CASTRO; REZENDE, 2018), o que fica demonstrada pela quantificação significativa de resultados demonstrados no capítuo das conclusões.

\section{ANÁlise dos dADOS}

Antes da realização das entrevistas, tomou-se ciência de que, via de regra, os analistas da área pericial contábil lotados MPF não tinham um feedback da qualidade de seu trabalho, dificultando, assim, a melhora de seu próprio desempenho profissional, conforme apontado por Chaudron (1977) e Chiavenato (2016). Assim, os peritos não recebem informações sobre se o relatório ou o laudo seriam realmente utilizados pelo usuário, se o documento escrito estava bem redigido, se atendia ou não as expectativas dos membros solicitantes; e se as peças entregues foram aceitas pelos juizes, bem como o resultado do andamento processual após a contribuição do perito.

Diante disso, questionou-se à amostra se o feedback de seu trabalho seria importante, e em caso positivo, o porquê dessa importância. Assim, todos os 12 entrevistados teceram comentários sobre a questão do feedback. Com o auxílio do software Nvivo e com o intuito de ilustrar os principais comentários, segregou-se as primeiras percepções da amostra.

Os entrevistados 1 e 9 mencionam que o feedback funciona como um direcionador de esforços e recursos, possibilitando saber se o objetivo da perícia foi alcançado e se foram atendidas as expectativas, de forma a direcionar os trabalhos seguintes. O Analista 1 complementa ao explicar que com a ausência desse retorno não há como saber se os trabalhos estão sendo realizados da forma que os membros esperam.

Para ele, no momento em que se entrega o trabalho, se perde tanto o contato com o processo, e com o próprio Procurador. Isso impossibilita conhecer dois fatores importantes: o primeiro, que o perito aprimore seu trabalho; o segundo é a chance de empregar o raciocínio em caso análogo. Complementa que há uma proposta da coordenação de que o membro avalie o trabalho pericial, mas que 
ainda não foi implementado.

No cargo de distribuição de processos, o Analista 5 cita que a questão de avaliar o trabalho do perito já foi pensado algumas vezes, inclusive a ponto de ser incluído no sistema pericial. Como contraponto, expõe que:

[...]a pessoa que vai avaliar o seu trabalho não é um contador "não achei interessante", mas de repente o contador que fez pensa 'puxa, esse trabalho foi um trabalho bom', mas na visão contábil, porque na visão jurídica não me adiantou nada, ele falou um monte de coisa aqui, mas ele não respondeu a minha pergunta". (Entrevistado 5)

O Analista 5 esclarece que eventualmente há retornos sobre alguns casos específicos em que o Procurador fica mais sensibilizado pela ajuda que o trabalho do perito lhe proporcionou, agradecendo-o. Contudo, deixa claro que, como o perito é servidor público, é seu dever de ofício fazer seu trabalho com qualidade, independentemente de haver feedback ou não.

Para o Entrevistado 6, a ausência de feedback é algo que "nós nos ressentimos muito aqui no $\mathrm{MPF}$, de não termos um retorno do nosso trabalho, uma indicação [...]. Abordagem não técnica, mas em relação à concisão e à objetividade do trabalho, seria sim um ponto qualitativo para nós". Explana que a medida que adotam é a de revisão por pares, mas que tal atitude esbarra no excesso de trabalho, especialmente de processos urgentes, pois "quando eu peço para meu colega fazer, ele está parando o dele", resumindo a revisão por às revisões gramaticais. Aduz que é difícil de outro perito opinar sobre sua metodologia de trabalho, haja vista que todos os analistas têm prazos curtos, mas eventualmente se obtém elogios de colegas de trabalho. Complementa que há uma avaliação pessoal de cada um, e que o perito sabe quando fez um trabalho bom.

O Entrevistado 7 acredita que não faz um mau trabalho justamente porque não há um feedback. Caso houvesse, as reclamações chegariam aos peritos, dando-lhes a oportunidade de melhorar seu desempenho profissional. Para ele, a falta desse retorno tem dois grandes pontos negativos. O primeiro é quando o perito está fazendo um trabalho "ruim" e continua a fazê-lo por anos, produzindo 
pareceres sem grande utilidade e atrasando processos. O segundo decorre da cobrança por celeridade, que é “justamente uma necessidade de piorar o conteúdo do nosso trabalho", pois com uma fila extensa de trabalho:

[...]se a gente está fazendo um trabalho mais minucioso do que deveria, a gente perde mais tempo. Então muitas vezes a gente poderia fazer um trabalho um pouco mais superficial e economizar uma semana, sendo que essa semana economizada a gente adiantava outro processo, que também economizaria uma semana, que economizaria outra semana, e a nossa fila poderia cair. (Entrevistado 7)

Este entrevistado explica que sem o feedback, o perito pode estar produzindo um trabalho ruim, achando que está bom, e para acelerar a análise e adiantar a fila, deixa-lo ainda pior. $\mathrm{O}$ analista, explana, que é difícil saber o que fazer, e por falta de orientação, faz-se a mesma coisa sempre. Contudo, não vê necessidade de elogios de Procuradores no sentido motivacional, de agradecimento, e sim como uma reflexão e uma crítica do seu trabalho.

A Entrevistada 8 explica que há sim um feedback mais frequente apenas do coordenador da câmara, com quem trabalha junto, em que são expostas críticas construtivas em relação ao parecer elaborado por ela. Porém, quando questionados sobre o feedback do Procurador, ela e o Entrevistado 9 esclarecem que a situação é a mesma enfrentada pelos outros analistas da SEAP: "são raras as vezes em que é dado um retorno".

A Entrevistada 10 sente falta de feedback de seus trabalhos, pois é importante para ela saber se o parecer elaborado rendeu algum fruto ou não para a atuação do órgão. Para ela, alguma função simples de avaliação no próprio sistema de gerenciamento pericial ajudaria. Antigamente, conta, havia uma avaliação em que, todo ano, o perito escolhia três Procuradores para avaliar o seu desempenho no ano anterior, com questões do tipo "o perito é assíduo?", "prestativo?", "ele atendeu as expectativas?", "ele trabalhou direitinho?", “o parecer dele foi razoável?" e "atendeu a sua demanda?". Contudo, para ela, o membro não tem condições de avaliar certas características por não possuir contato com o perito, o que dificulta 
seu conhecimento sobre pontos do tipo assiduidade, proatividade e se o perito tem conhecimento técnico ou não tem.

O Entrevistado 11 enfatiza que, essa carência no retorno dos trabalhos realizados resulta no fato do perito não saber, ou se o Procurador está entendendo o parecer, ou se foi útil para ele. Em sua percepção, "são pouquíssimas vezes que conversam com a gente", pois há a entrega do laudo ou do parecer, e se o perito cumpriu o prazo, nunca mais se fala sobre o processo.

O Entrevistado 12 corrobora com as percepções anteriores ao aduzir que o feedback é um direcionador do trabalho. Para ele, se o Procurador não reclamou, é porque o trabalho realizado está bom. Contudo, salienta que cada membro tem o próprio jeito de trabalhar, então pode acontecer de o perito fazer "o mesmo parecer técnico, um Procurador vai gostar e o outro pode não gostar".

Em termos práticos, explica que ao entregar um parecer muito detalhado, o membro pode considerar demasiadamente explicado, ao ponto de ser quase exaustivo e pouco conciso. A partir dessa situação, conta que poderia se mudar a forma de se fazer os pareceres, buscando ser mais sucinto. Nessa nova realidade, poderia ouvir de outro Procurador que o parecer não está dando a devida ênfase nas partes importantes. Em síntese, explica que "não tem como a gente agradar a todos. Não tem. Então nesse aspecto, esse feedback do Procurador não seria tão importante assim". Por outro lado, o retorno após o procedimento pericial é, na sua percepção, mais importante, pois embora o parecer técnico seja para o Procurador, o objetivo final é dar o melhor retorno possível para a sociedade.

Na SPEA, o Entrevistado 2 explica que se questionar o Procurador, o mesmo dirá que o trabalho desenvolvido é ótimo "porque é natural essa generosidade", mas não é tão fidedigno do que se houvesse uma nota mais individualizada por produto entregue. Explana que as vezes são necessários relatórios com limitação de dados e, embora se faça o melhor possível, não atende à demanda. Para ele, obter o retorno sobre o trabalho seria proveitoso, pois seria possível conhecer as dificuldades, e saber onde melhorar e o que potencializar.

O Entrevistado 3 expõe que não há um feedback, o que implica no desconhecimento do perito quanto à utilidade e ao cumprimento do objetivo inicial de seu trabalho, e que as críticas sobre a qualidade 
de seu trabalho contribuiriam e agregariam nos relatórios seguintes. Cita casos em que, ao entregar seu relatório, o Procurador pede uma maior ênfase em alguns pontos, mas que isso não é propriamente um feedback, e sim uma complementação.

O Entrevistado 4 expõe que, via de regra, não há nem o retorno sobre o trabalho, nem sobre o resultado da ação. Em alguns poucos casos, o "Procurador até comenta 'ah, foi bom, deu esse resultado', 'ah, foi bom, gerou isso aqui'. E outros a gente não sabe, na verdade, como foi usado, qual o contexto". Para ele, há uma dificuldade de se entender o contexto, pois os Procuradores e os assessores conseguem se inteirar de todo o contexto, mas os analistas não, o que limita seu trabalho apenas aos pontos suscitados por aqueles.

Assim, à exceção do Entrevistado 5, que não se manifestou sobre os benefícios do feedback, todos os demais analistas da área pericial contábil do MPF apontam que tal retorno sobre a qualidade de sua atuação seria um bom direcionador de seu trabalho, conforme exposto por Chiavenato (2016), sendo que alguns analistas demonstram a necessidade enquanto outros dispensam.

\section{RESUltados}

Os 12 entrevistados responderam sobre a importância do feedback na rotina profissional, sendo a significativa maioria indicando que trata-se de aspecto impotante e necessário para a utilidade e qualidade dos trabalhos. Entre os 12 respondentes, 11 indicaram que o feedback é importante, enquanto apenas um considerou desnecessário para o desenvolvimento do trabalho.

Os achados da pesquisa são relevantes em indicar a ausência de feedback entre os peritos contábeis do MPF. Por meio da análise das entrevistas percebe-se a frustração dos entrevistados pela ausência desse instrumento de retroalimentação, ao indicarem que em raras oportunidades é dado um retorno (E8, E9, E11) perdendo-se o contato com os passos seguintes do processo (E1) e consequentemente há um desconhecimento quanto à utilidade e ao cumprimento do objetivo (E3) e da eficácia do seu trabalho (E10). Essas limitações tendem a diminuir a motivação dos peritos, pois de acordo com Martins e Bermejo (2018), também desejam receber feedback sobre suas ideias e que elas sejam reconhecidas. 
Devido a ausência do feedback, resultam problemas ou ineficiências (E2) no trabalho do perito como o desconhecimento de deficiências ou fatores a melhorar (E1, E2, E3), falta de repertório para analogias (E1, E4), compreensibilidade limitada (E11), possibilidades de incompletudes ou de atrasos na entrega dos relatórios (E7), trabalhos excessivamente pontuais ou prolixos (E12), e por fim a repetição do trabalho de má qualidade (E7).

Os peritos indicaram oportunidades de implantação de ferramenta de feedback no sistema de gerenciamento pericial (E10), preferencialmente individualizado por produto entregue haja vista que muitos processos carecem de elementos necessários para subsidiar um parecer conclusivo (E2). Mesmo sem um sistema de feedback, os relatos indicam a inexistência de reclamações, o que poderia ser uma sinalização de ausência de problemas na elaboração dos relatórios (E7), depreendendo-se que são satisfatórios e atendem às demandas (E12). Outros fatores também são relevantes para um bom desempenho, como o benefício próprio e a ideologia (LAKHANI; WOLF, 2005), e esses fatores intrínsecos teriam maior força do que os extrínsecos, como o feedback (KAUFMANN; SCHULZE; VEIT, 2011).

Há que se considerar a capacidade do usuário formado na área de Direito dar um feedback sobre um tema Contábil que deve restringir-se a aspectos de utilidade e compreensibilidade, ou mesmo sobre aspectos organizacionais haja vista que são atores que não mantém contato profissional direto (E10, E12). Uma alternativa para suprir a lacuna de feedback técnico seria a revisão ou avaliação por pares, mas não implementada por carência de pessoal (E6).

Para Wijnhoven, Ehrenhard e Kuhn (2015) é importante a forma de utilização que se dá ao feedback; de certa forma, o feedback do feedback; pois seria preciso processas as sugestões, examinar cuidadosamente cada sugestão e dar uma resposta precisa do porquê de certas idéias ou partes dela não terem sido implementadas. Além disso, possíveis participantes são mais propensos a se engajar se acreditarem que suas idéias e sugestões serão implementadas.

\section{Considerações finais}

A pesquisa foi desenvolvida em torno da discussão sobre o feedback acerca do trabalho realizado pelos analistas periciais contá- 
beis no MPF. Assim, realizando entrevistas presenciais no Distrito Federal, Rio Grande do Sul, Paraná e São Paulo, totalizando uma amostra de 12 analistas da área pericial contábil no MPF. O estudo teve como objetivo verificar a importância do feedback para as práticas profissionais desses analistas.

Os entrevistados consideram importante o processo de feedback do trabalho prestado, com o inuito de direcionar as futuras análises e concentrar o tempo empregado em cada caso de maneira mais eficiente, corroborando a importância destacada no estudo de Davis, Farrel e Ogilby (2010).

$\mathrm{Na}$ atual situação, os analistas não possuem o retorno sobre o trabalho feito, semelhante aos achados de Martinez (2013), para outro órgão perícial. O feedback poderia trazer alguns benefícios, como o feedback sobre a qualidade do trabalho fornecida pelo usuário de maneira abrangente, haja vista que o usuário jurídico não tem o conhecimento técnico contábil, e consequentemente não teria um critério ideal de avaliação do trabalho pericial. Nessa situação, sugere-se um sistema de avaliação mais simples, questionando o usuário solicitante se o trabalho recebido foi de fácil entendimento, conciso, claro, objetivo, consistente e útil.

A outra perspectiva é a apreciação por pares, com conhecimento técnico e experiência semelhante, que poderia ser mais útil quanto a assertividade dos procedimentos realizados. Conforme mencionado, isso demanda a disponibilidade de pessoal, o que muitos órgãos não dispõem, inclusive o objeto da pesquisa. Além disso, é importante ao profissional o retorno sobre a utilidade do produto pericial para o processo judicial como um todo, seja para uma acusação ou arquivamento, mas isso pode demorar muitos anos. O conhecimento sobre o desfecho de um processo pode indicar se os procedimentos realizados por eles deu bons resultados ou não, tornando viável a "replicação" de determinados procedimentos e metodologias em casos semelhantes.

Os analistas periciais prestam um serviço importante, útil e de grandes implicações no processo decisório dos procuradores da República. Na medida em que se estabeleça um sistema e canais para feedback, os analistas periciais poderão melhorar suas práticas profissionais, dimensionar melhor suas atividades e recursos de 
que necessitam, além de cuidarem de sua educação continuada e reciclagem técnica profissional.

Como limitação dessa pesquisa, tem-se que não se questionou aos destinatários finais do trabalho realizado pelos analistas (Procuradores da República e Magistrados) sobre a relevância de um sistema de feedback para aqueles profissionais. Esta pesquisa abordou apenas um lado do processo, ainda que não seja atribuição dos analistas do MPF proporem melhorias no órgão, suas percepções sobre tais proposições são importantes.

Assim, sugere-se, para pesquisas futuras, a investigação do feedback ante os Procuradores da República sobre o trabalho realizado pelos analistas da área pericial contábil do MPF. Uma forma de melhorar a prestação desses serviços é saber como e em que medida os laudos periciais contábeis, enquanto relatórios contábeis destinados a apoiar processos decisórios, têm contribuído para que as decisões tomadas pelos procuradores sejam as mais acertadas possíveis.

Também se sugere que esses mesmos profissionais sejam questionados sobre a qualidade dos pedidos de análise realizados pelos demandantes, haja vista que, se uma análise, em resposta a esse pedido, foi realizada com carências, pode-se supor que o inverso também pode ocorrer, ou seja, o pedido de análise pode vir com pontos in dubio, o que dificultaria o entendimento do analista, e consequentemente, sua análise.

\section{REFERÊNCIAS}

ALBERTO, V. L. P. Perícia contábil. 5. ed. São Paulo, SP: Atlas, 2012.

ANGROSINO, M. Etnografia e observação participante. Porto Alegre: Artmed, 2009.

ANJOS, L. C. M. SANTANA FREIRE, R.; SALES, J. D. A.; FREITAS, A. R. F.; SILVA, D. J. C. A Utilização do Laudo Pericial Elaborado Pelo Perito Contador: um estudo descritivo nas varas cíveis estaduais na cidade de Maceió-Alagoas. Revista de Contabilidade da UFBA, Salvador, v. 4, n. 1, p. 23-38, jan./abr., 2010.

BASTOS, L. T. A prova pericial contábil na visão dos Procuradores do Ministério Público Federal em Goiás. 2013. 43f. Monografia (Trabalho de Conclusão de Curso) - Universidade Federal de Goiás, Goiânia, 2013.

BLEIL, C.; SANTIN, L. A. B. A perícia contábil e sua importância sob o olhar dos magistrados. Revista de Administração e Ciências Contábeis do IDEAU, Getúlio Vargas, v. 3, n. 7, p. 2-17, fev./jul., 2008. 
BRASIL. Ministério Público Federal (MPF). Escola Superior do Ministério Público da União - ESMPU. Por dentro do MPF. 6. ed. Brasília: PGR/SECOM, 2010.

BRASIL. Ministério Público Federal. Fiscal da lei, cível e criminal. 2017.

CARVALHO, G. B. de. Como motivar funcionário públicos: o caso dos peritos do Instituto Nacional de Criminalística. 103f. Dissertação (Mestrado em Administração) - Escola de Administração Pública e de Empresas, Rio de Janeiro, 2012.

CASTRO, J. M.; REZENDE, S. F. L. Validade e Confiabilidade de Estudos de Casos Qualitativos em Gestão Publicados em Periódicos Nacionais. Revista Organizações em Contexto, v. 14, n. 28, p. 29-52, 2018.

CAVEDON, N. R. "Isso aqui é uma fábrica de loucos": a saúde mental dos servidores do Departamento de Criminalística do Instituto-Geral de Perícias do Rio Grande do Sul. In: EnANPAD, 32., São Paulo: 2009. Anais... São Paulo: USP, 2009.

CERVO, A. L.; BERVIAN, A.; SILVA, R. da. Metodologia científica. 6. ed. São Paulo: Pearson Prentice Hall, 2007. E-Book.

CESTARE, T. B.; PELEIAS, I. R.; ORNELAS, M. M. G. O laudo pericial contábil e sua adequação às normas do Conselho Federal de Contabilidade e à doutrina: um estudo exploratório. Revista de Contabilidade do Mestrado em Ciências Contábeis (UERJ), Rio de Janeiro, v. 12, n.1, p. 1-14, jan./abr., 2007.

CHAUDRON, C. A Descriptive Model of Discourse in the Corrective Treatment of Learners'Errors, 1. Language learning, v. 27, n. 1, p. 29-46, 1977.

CHIAVENATO, I. Desempenho humano nas empresas: como desenhar cargos e avaliar o desempenho para alcançar resultados. 7. ed. Barueri, SP: Manole, 2016.

COLAUTO, R. D.; BEUREN, I. M. Coleta, análise e interpretação dos dados. In: BEUREN, I. M. (Org.). Como elaborar trabalhos monográficos em Contabilidade: teoria e prática. 3. ed. São Paulo: Atlas, 2006.

CONSELHO FEDERAL DE CONTABILIDADE. (CFC). Normas Brasileiras de Contabilidade: NBC TP 01 - Norma Técnica de Perícia Contábil. Brasília: Conselho Federal de Contabilidade, 2015.

DAFT, R. Administração. São Paulo: Thomson Learning, 2007.

DAVIS, C.; FARRELL, R.; OGILBY, S. Characteristics and skills of the forensic accountant. New York: AICPA, 2010.

FAGUNDES, J. A.; POSSAMAI, A. K.; CIUPAK, C.; LAVARDA, C. E. F. Perícia Contábil Trabalhista: um estudo multi-caso em processos lotados no Tribunal de Justiça do Trabalho da Comarca de Sorriso (MT). Revista Contexto, Porto Alegre, v. 8, n. 14, p. 01-23, 2008.

FERREIRA, T. B.; FERREIRA, T. B., MIRANDA, L. C., MEIRA, J.; SANTOS, A. A. Qualidade do Laudo Pericial Contábil Trabalhista: percepção dos Magistrados das Varas Trabalhistas do Recife. Registro Contábil, Maceió, v. 3, n. 3, p. 54-70, 2012.

FLICK, U. Desenho da pesquisa qualitativa. Porto Alegre: Artmed, 2011. 
GIBBERT, M.; RUIGROK, W. The "what" and "how" of case study rigor: Three strategies based on published work. Organizational research methods, v. 13, n. 4, p. 710-37, 2010.

GIL, A. C. Como elaborar projetos de pesquisa. 6. ed. São Paulo: Atlas, 2017. E-Book.

GIL, A. C. Métodos e técnicas de pesquisa social. 6. ed. São Paulo: Atlas, 2008. E-Book.

GUALDA, C. M. de A. A motivação no serviço público federal: o caso da perícia criminal federal. 84f. Dissertação (Mestrado em Administração) - Escola de Administração Pública e de Empresas, Rio de Janeiro, 2013.

HOOG, W. A. Z. Prova Pericial Contábil: teoria e prática. 14. ed. Curitiba: Juruá, 2017. E-Book.

KAUFMANN, N.; SCHULZE, T.; VEIT, D. More than fun and money. Worker Motivation in Crowdsourcing-A Study on Mechanical Turk. In: AMCIS. 2011. p. 1-11..

LAKHANI, K. R.; WOLF, R. G. Why hackers do what they do: Understanding motivation and effort in free/open source software projects. Perspectives on Free and Open Source Software, MIT Press, 2003.

MAGALHAES, A. D. F.; SOUZA, C. D.; FAVERO, H. L.; LONARDONI, M. Perícia Contábil: uma abordagem teórica, ética, legal, processual e operacional - casos praticados. 7. ed. São Paulo: Atlas, 2009.

MARTINEZ, S. C. A efetividade do laudo pericial: um estudo sobre a influência do laudo pericial de informática na decisão judicial. 62f. Dissertação (Mestrado em Administração) - Escola de Administração Pública e de Empresas. Rio de Janeiro, 2013.

MARTINS, R. Brasil piora em ranking de corrupção com provas da Lava Jato. Revista EXAME, São Paulo, 27 jan. 2016.

MARTINS, T. C. M.; BERMEJO, P. H. S. Os Fatores Determinantes da Participação na Produção Coletiva de Ideias para Solução de Problemas Públicos. Revista de Administração Pública, v. 52, n. 3, p. 417-434, 2018. DOI: http://dx.doi.org/10.1590/0034-7612160487

MEDEIROS, T. A.; NEVES JÚNIOR, I. J. das. A qualidade do laudo pericial elaborado pelo perito contador na visão de magistrados do Rio de Janeiro e Brasília. Revista Brasileira de Contabilidade, n. 159, p. 44-57, 2006.

MENDONÇA, J. F.; JUNIOR, L. R. D. L.; SLOMSKI, V. G.; PELEIAS, I. R. Relevância do Laudo Pericial Contábil na tomada de decisão judicial: Percepção de um juiz. RIC-Revista de Informação Contábil, v. 6, n. 2, p. 21-39, 2012.

MINAYO, M. C. de S. Ciência, técnica e arte: o desafio da pesquisa social. In: MINAYO, M. C. de S. (Org.). Pesquisa Social: teoria, método e criatividade. 25. ed. Petrópolis: Vozes, 2007.

MOREIRA, B. L. Dicas de Feedback: A Ferramenta Essencial da Liderança. Rio de Janeiro, RJ: Qualitmark, 2009.

NEVES JÚNIOR, I. J. MOREIRA, S. A.; RIBEIRO, E. B.; SILVA, M. C. D. Perícia Contábil: estudo da percepção de juízes de Primeira Instância na Justiça do Trabalho sobre a qualidade e a relevância do trabalho do perito. Revista Brasileira de Gestão de Negócios, São Paulo, v. 15, n. 47, p. 300-320, abr./jun., 2013. 
NEVES JÚNIOR, I. J.; COSTA, V. A.; PEREIRA; C. D. S. Perícia Contábil e o trabalho desenvolvido pelo analista do Departamento de Cálculos e Perícias da Advocacia Geral da União. In: Congresso USP de Controladoria e Contabilidade, 8., São Paulo: 2008. Anais... São Paulo: USP, 2008.

NEVES JÚNIOR, I. J.; MOREIRA, E. M. S. Perícia contábil: uma ferramenta de combate ao crime organizado. Revista de Educação e Pesquisa em Contabilidade, Brasília, v. 5, p. 126153, nov., 2011.

OLONGO. Itinerário do amadurecimento do Judiciário. Revista Consultor Jurídico, São Paulo, 7 jun. 2014.

RICHARDSON, R. J. Pesquisa Social: métodos e técnicas. 3. ed. São Paulo: Atlas, 1999.

SÁ, A. L. de. Perícia contábil. 10. ed. São Paulo: Atlas, 2011.

TRANSPARENCY International. Corruption Perceptions: Index 2015.

TSUNODA, M. A. O processo de construção da identidade do profissional perito criminal federal. 83f. Dissertação (Mestrado em Administração) - Escola de Administração Pública e de Empresas. Rio de Janeiro, 2011.

VIEIRA, A. M.; RIVERA, D. P. B. A Hermenêutica no Campo Organizacional: duas possibilidades interpretativistas de pesquisa. Revista Brasileira de Gestão de Negócios, v. 14, n. 44, p. 261-273, 2012.

YIN, R. K. Validity and generalization in future case study evaluations. Evaluation, v. 19, n. 3, p. 321-32, 2013.

Recebido em: 11-5-2019

Aprovado em: 24-10-2019

Avaliado pelo sistema double blind review.

Disponível em http://mjs.metodista.br/index.php/roc 